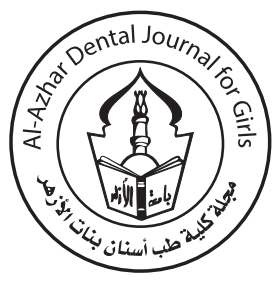

\title{
Efficacy of Different Surface Treatments on the Bond Strength of Resin cement to Zirconia Ceramic
}

\author{
Eman T. Elkallaf ${ }^{1 *}$, Atef F.Ahmed ${ }^{2}$, Eman Essam $^{3}$, Suad M. Hasan ${ }^{4}$
}

Codex : 63/20.10

azhardentj@azhar.edu.eg

http://adjg.journals.ekb.eg

DOI: $10.21608 /$ adjg.2020.13536.1162

Restorative Dentistry

(Removable Prosthodontics, Fixed

Prosthodontics, Endodontics, Dental Biomaterials, Operative Dentistry)

\section{KEYWORDS}

$\mathrm{Al}_{2} \mathrm{O}_{3}$ particles,

Hand grinding,

Laser etching,

Zirconium ceramic

\begin{abstract}
Purpose: The plan for this study was to anatomise the effect of alternative surface treatments to enhance bonding to zirconia. Materials and Methods: forty discs of zirconia (Prettau,zircon zhan, Italy) were prepared using Isomet 4000 precision Saw then discs were divided into 5 groups. Group 1, control; Group2, zirconia discs were treated with50-mm $\mathrm{Al}_{2} \mathrm{O}_{3}$ particles; Group 3, zirconia discs were received hand grinding; Group 4, zirconia discs were treated by a CO2 laser and Group 5, zirconia discs were treated using ERYAG laser. Composite resin discs were constructed and cemented to zirconia samples with panavia cement. For the bond strength test, a universal testing machine was used. Results: the highest shear bond strength was recorded for (Hand grinding) group (2) while the lowest mean value was recorded for control group (1). Conclusions: Treatment of Zirconia Surfaces with hand grinding or sandblasting increased shear bond strength. Treatment of Zirconia with CO2 and ERYAG lasers increased shear bond strength of zirconia, with the $\mathrm{CO} 2$ laser being higher than ERYAG laser.
\end{abstract}

\section{INTRODUCTION}

Ceramic restorations are most qualified esthetically restorations currently available. All Ceramics divided micro-structurally into 4 categories: Group 1- Glass based systems (mainly silica with sodium and potassium alumino silicates). Croup 2- Glass based systems with crystalline fillers (IPS Empress II, IPS E-max). Croup 3- Crystalline

- Paper extracted from master thesis titled "Efficacy of Different Surface Treatments on the Bond Strength of Resin cement to Zirconia Ceramic"

1. Demonstrator of Crowns and Bridges, Faculty of Dental Medicine for Girls, Al-Azhar University, Cairo, Egypt

2. Professor and head of Crowns and Bridges Department, Faculty of Dental Medicine for Girls, Al-Azhar University, Cairo, Egypt

3. Professor of Crowns and Bridges, Faculty of Dental Medicine for Girls, Al-Azhar University, Cairo, Egypt

4. Lecturer of Crowns and Bridges, Faculty of Dental Medicine for Girls, Al-Azhar University, Cairo, Egypt

* Corresponding author email: , emantaha198@gmail.com 
based systems with glass fillers (In-Ceram). Croup 4-Polycrystalline solids. Zirconia based ceramics are the newly developed ${ }^{(1)}$. To give high quality and improved style, zirconium oxide has been utilized as a center material; porcelain is then melded to the external surface. Zirconium oxide has been appeared to be more translucent than metal substructures when ceramic is fused to the external surface ${ }^{(2)}$.

However, a typical issue with veneered zirconium oxide contrasted with metal-ceramic crowns is increased crack rate, potentially caused by difference in coefficients of thermal expansion. To diminish the veneering fracture, manufacturers have recently marketed monolithic zirconia restorations (3). Resin cement are the material of decision due to high physical properties, lowsolubility \& high wear resistance and closure of margin . The life time of indirect restoration depends on cement adequacy between dental tissues and Resin cement.

Based on the treatment of tooth structure, resin cements are total-etch resin cements, self-etch resin cement, and self-adhesive resin cements.Selfadhesive resin cements can bond to tooth surface without using bonding adhesive ${ }^{(4)}$.

For the most part, zirconia restorations do not form a proper bond to tooth structure and acid etching technique cannot cause topographic changes on zirconia ceramic surface. Evidence shows that good bond to zirconia ceramics is obtained by cement material containing phosphate monomer in its composition. Surface treatment is done using techniques, for example, surface grinding, air abrasion with $\mathrm{Al}_{2} \mathrm{O}_{3}$ or silicate particles, selective infiltration etching and recently, irradiation of lasers, for example, Carbon dioxide,Erbium:YAG and neodymium:YAG for zirconia ceramic ${ }^{(5)}$. The plan for this study was to estimate the effect of alternative surface treatments to enhance bonding to zirconia .

\section{MATERIALS AND METHODS}

At the present study, Forty discs of Prettau zirconia $(6 \mathrm{~mm}$ in diameter, $3 \mathrm{~mm}$ thickness) were prepared using Isomet 4000 precision Saw(Isomet
4000, Buehler,USA). The obtained discs were then sintered in $\mathrm{HTF}$ (Wholesale sintering furnace, DS1700MX, Mainland, China) at $1600{ }^{\circ} \mathrm{C}$ for eight hours including cooling. During this process a 3-dimensional volumetric shrinkage of the milled discs of approximately $20 \%$ took place that is why the discs were milled approximately $20 \%$ larger. The dimensions of the discs after shrinkage were $6 \mathrm{~mm}$ in diameter, $3 \mathrm{~mm}$ in thickness. 5 groups $(\mathrm{n}=8)$ were constructed according to surface treatment.

\section{Types of different surface treatment:}

Group 1: Control group.

Group 2: Sandblasting was completed to eight zirconia discs using $50 \mu \mathrm{m}$ Aluminum oxide particles using an airborne particle-abrasive device (Renfert,Germany). The discs were mounted at a distance of $10 \mathrm{~mm}$ in a metallic holder. Sandblasting was done for $20 \mathrm{sec}$, with $3 \mathrm{bar}$ pressure.

Group 3: Samples were ground using diamond rotary cutting instrument in a high-speed hand piece for $10 \mathrm{sec}$ in one direction movements under water irrigation. The grinding speed was $150000 \mathrm{rpm}$.

Group 4: Samples were treated by $\mathrm{CO}_{2}$ laser at zero distant. Wave length was 10.6 um and delivered through an articulating arm. The laser power was 3-watt Power for 10 seconds, energy density of $265.39 \mathrm{~J} / \mathrm{cm} 2$, pulse duration of $160 \mathrm{~ms}$ ).

Group 5: Samples were treated by ER-YAG laser at zero distant. Each disc was irradiated with $2 \mathrm{~W}$ output power, energy density of $200 \mathrm{~mJ}$, pulse duration of $50 \mu \mathrm{s}$. The zirconia disc area was laser lased with water irrigation and air-cooling for 10 seconds.

\section{Composite discs construction:}

In order to standardize the shape and size of the samples, a specially designed Teflon mold is used for this purpose. Layers of composite resin were incrementally pressed into the mold and were cured for 30 seconds at a distance $1 \mathrm{~mm}$ utilizing a light polymerizing unit (Astralis 3; Ivoclar AG, Schaan FL, Liechtenstein, Targis quick, 230V,50-60Hz,100VA). Forty composite discs were prepared. 


\section{Cementation of the samples:}

One drop of ED Primer II Liquid A and B were mixed on mixing pad. The mixture was utilized within 5 minutes after mixing. Composite discs were Painted with ED Primer II utilizing micro brush and left for 30 seconds. Excess ED Primer II Liquid was removed by blown air. The cementation of the composite discs to the zirconia samples was done PANAVIA F2.0 cement. The same amounts of paste A and B were applied on the mixing pad and mixing for twenty sec into homogenous paste and applied on the surface of samples using plastic spatula.

\section{Cementation Procedures:}

The disc of composite was seated above the opposing zirconia disc. To ensure standardization of the load applied during cementation procedure and the direction of the load, a specially designed cementing device was used.Each surface of the disc was cured for 20 seconds.

\section{Thermal cycling:}

All specimens were thermo cycled so as to mimic the thermal change in oral condition. All discs were repeatedly soaked in a deionized water bath of $5^{\circ} \mathrm{C}$ and $55^{\circ} \mathrm{C}$ with dwell times $25 \mathrm{~s}$ in each water bath and a lag time $10 \mathrm{~s}$. using a thermal cycle device (Robota automated thermal cycle; BILGE, Turkey) for 3000 cycles then the shear strength values of specimens were estimated.

\section{Shear Bond Strength test:}

Shear test was designed to evaluate the bond strength. The load required for de bonding was recorded in Newton. The load at failure was divided by bonding area to express the bond strength in Mpa:

$\tau=\mathrm{P} / \pi \mathrm{r}^{2}$ where: $\tau=$ shear bond strength $(\mathrm{MPa})$, $\mathrm{P}=$ load at failure $(\mathrm{N})$

$\pi=3.14$ and $r=$ radius of resin $\operatorname{disc}(\mathrm{mm})$

\section{Evaluation of mode of failure:}

All the fractured samples were evaluated using digital stereomicroscope (Digital microscope, Guangadong, China) and photographed with a builtin camera (Carl Zeiss, Aalen, Germany) which is connected to an IBM compatible computer.

\section{Scanning Electron Microscope Examination:}

To estimate the effect of surface treatment on the surface of zirconia, four additional samples for each group were prepared for SEM Using SEM Model Quanta 250 FEG .

\section{Statistical analysis of the shear bond strength:}

The collected data were statistically analyzed using SPSS software (Statistical Package for the Social Sciences, version 19, SPSS Inc. Chicago, IL, USA).Significance was adopted at $\mathrm{p}<0.05$.

\section{RESULTS}

It was discovered that the highest shear bond strength mean value was recorded for (Hand grinding) group (3), followed by (Sandblasting) group (2), $\left(\mathrm{CO}_{2}\right.$ laser) group (4) and (ER-YAG Laser) group (5).While the lowest mean value was recorded for control group (1) (4.803MPa), table(1) \& figure(1).

\section{Comparison of Shear bond strength between different surface treatments:}

It was discovered that the highest shear bond strength mean value was recorded for (Hand grinding) group (3) (17.075MPa), followed by (Sandblasting) group (2) (14.852MPa) then $\left(\mathrm{CO}_{2}\right.$ laser) group (4) (11.742MPa). While the lowest mean value was recorded for (ER-YAG Laser) group (5) (4.1536MPa). The difference between different surface treatment groups was statistically significant as revealed with one-way ANOVA test $(\mathrm{p}<0.05)$. Student $\mathrm{T}$ Test showed that there was no significant difference between hand grinding and sandblasting (air abrasion) $\mathrm{P}=0.526$. There was a significant difference between laser type I and laser type II (ERYAG) $\mathrm{P}=0.0001$. Table (2) 
Table (1): Shear bond strength results (Mean values \pm SDs) as function of zirconia surface treatments:

\begin{tabular}{|c|c|c|c|c|}
\hline \multirow{2}{*}{ Different surface treatments } & \multirow{2}{*}{ No. of discs } & \multicolumn{3}{|c|}{ Shear bond strength (MPa) } \\
\cline { 3 - 5 } & & Range & Mean \pm SD & Median \\
\hline Group 1 (Control group) & $\mathbf{8}$ & $2.197-6.121$ & $4.803 \pm 1.436$ & 5.259 \\
\hline Group 2 (sand blasting) & $\mathbf{8}$ & $7.950-23.913$ & $14.852 \pm 5.475$ & 16.190 \\
\hline Group 3 (hand grinding) & $\mathbf{8}$ & $8.132-30.341$ & $17.075 \pm 7.956$ & 17.111 \\
\hline Group 4 (CO, laser) & $\mathbf{8}$ & $9.540-15.063$ & $11.742 \pm 1.736$ & 11.293 \\
\hline Group 5 (ER-YAG laser) & $\mathbf{8}$ & $5.297-9.323$ & $7.471 \pm 1.439$ & 7.562 \\
\hline $\begin{array}{c}\text { F value } \\
\text { P }\end{array}$ & & & 10.254 & $0.0001 *$ \\
\hline
\end{tabular}

* Significant $(P<0.05)$

Table (2): Comparison of Shear bond strength (MPa) between differently treated zirconia samples:

\begin{tabular}{|c|c|c|c|c|}
\hline \multirow{2}{*}{ Surface treatments } & \multirow{2}{*}{$\begin{array}{c}\text { No. of } \\
\text { discs }\end{array}$} & \multicolumn{3}{|c|}{ Shear bond strength (MPa) } \\
\hline & & Range & Mean \pm SD & Median \\
\hline Group 3 (hand grinding) & 8 & $8.132-30.341$ & $17.075 \pm 7.956$ & 17.111 \\
\hline Group 2 (air abrasion) & 8 & $7.950-23.913$ & $14.852 \pm 5.475$ & 16.190 \\
\hline Group 4 ( $\mathrm{CO}_{2}$ laser $)$ & 8 & $9.540-15.063$ & $11.742 \pm 1.736$ & 11.293 \\
\hline Group 5 (ER -YAG laser) & 8 & $5.297-9.323$ & $7.471 \pm 1.439$ & 7.562 \\
\hline $\begin{array}{c}\text { F value } \\
\mathbf{P}\end{array}$ & \multicolumn{4}{|c|}{$\begin{array}{c}5.640 \\
0.004 *\end{array}$} \\
\hline t- test $P$ & \multicolumn{4}{|c|}{$\mathrm{G} 3$ vs $\mathrm{G} 2, \mathrm{P}=0.526 \mathrm{G} 4$ vs $\mathrm{G} 5, \mathrm{P}=0.0001 *$} \\
\hline
\end{tabular}

* Significant $(P<0.05)$

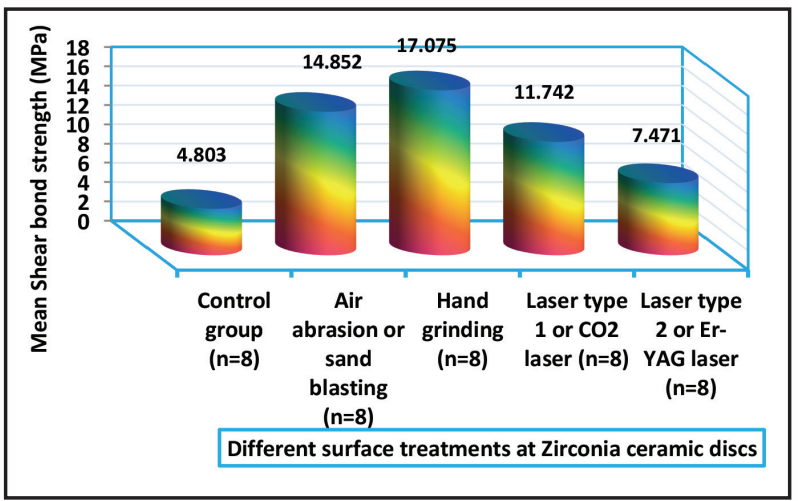

Figure (1) Column chart comparing shear bond strength mean values for all groups as function of surface treatment.

\section{Mode of failure analysis:}

Failure types were noted as cohesive, adhesive, or mixed failure among all the surface treated groups.

1. Cohesive failure: failure within the cement layer.

2. Adhesive failure: failure between the zirconia and resin cement

3. Mixed failure: combination of the previous two types 
Scanning electron microscope analysis for each group:

The SEM image of the untreated zirconia surface showed smooth surface without any morphologic changes.

SEM examination of the sandblasting group showed rough and numerous micro-porosities with shallow pits.

SEM of the Hand grinding group showed numerous parallel scratches introduced by grinding tool were clearly visible, increasing the surface area and roughness compared with control samples (Figure 2).

SEM For CO2 laser surface treatment, showed a rough surface, globules with microcracks. Irregularities on the zirconia surface (Figure2).

SEM For ER-YAG group, showed roughness, irregularities and numerous micro-porosities on the surface of zirconia without microcracks.

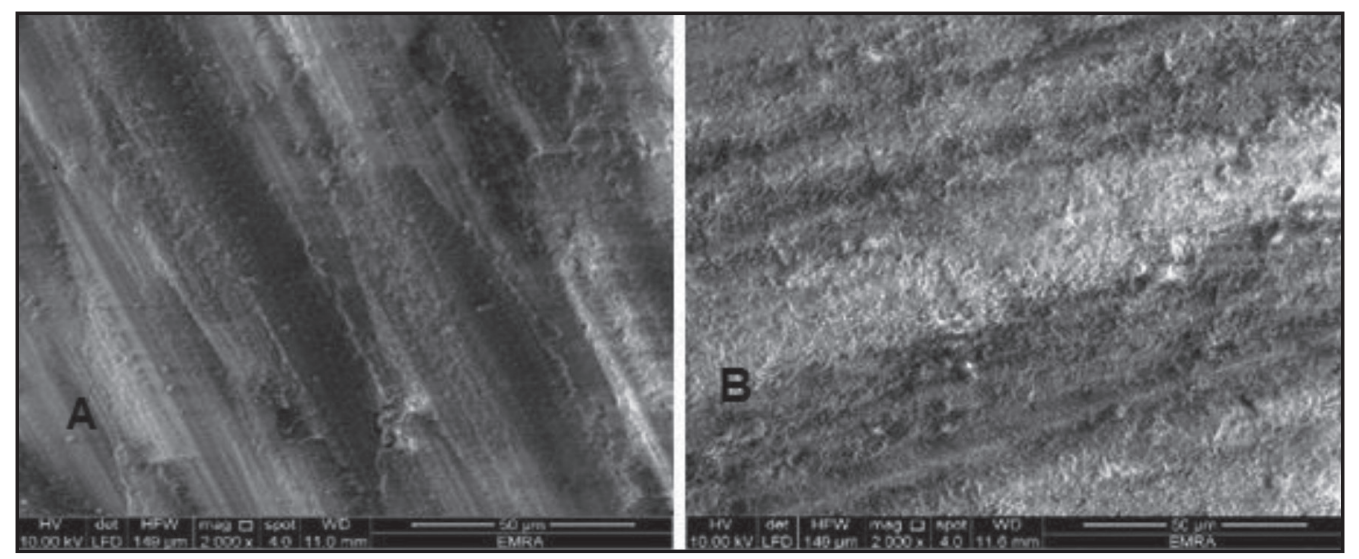

Figure (1) SE photomicrograph, demonstrating zirconia surface after being treated with Hand grinding(A) and CO2laser (B).

\section{DISCUSSION}

Y-TZP have been suggested for oral restoration. Its properties, for example, high mechanical strength, flexural resistance, and long-term stability make zirconia ceramics suitable for esthetic crowns, bridges. Zirconia ceramics have high mechanical properties. Flexural strength of zirconia is $900-1200$ MPa. Fracture resistance higher than 2,000 N.The utilization of zirconia material in this study is because the high strength and fracture toughness of zirconia arise from the partially stabilized structure of zirconia ${ }^{(6-9)}$.

Clinical success of the restoration strongly depends on the cementation ${ }^{(10)}$. Cementation of Zirconia to teeth either by conventional cements or resin cements. Due to good marginal seal, high retention and high fracture resistance of resin cements making them better ${ }^{(11)}$. Using resin cement with short crowns, large amount of tooth would be preserved $^{(12)}$.

In this study composite discs were used instead of tooth tissue, where the micro-structural variations of tooth tissues, which could result in ambiguous results, were dodged ${ }^{(13)}$. Dual-cured resin cement has been used to allow total polymerization of the resin agent even at areas which curing not reach $^{(14,15)}$. Panavia cement which has 10-MDP has been used ${ }^{(16,17)}$. MDP have chemical reaction with zirconia $^{(18)}$. Clinical success of ceramics rely upon proper adhesion to dental cements, which decrease micro leakage, increase retention, and increase fracture resistance ${ }^{(19,20)}$. 
Zirconia composed of many crystals without glass So, Zirconia cannot be treated by acid etching. Along these lines, airborne abrasion, grinding could be used to treat Y-TZP and as of late, irradiation of lasers such as $\mathrm{CO}_{2}$ and ER: YAG for Y-TZP ceramic ${ }^{(5,6)}$. Thermocycling was made to simulate thermal changes that happen orally ${ }^{(21)}$. Discs were oppressed to 3000 cycles between 5 and $55 \mathrm{C}^{\circ}{ }^{(22)}$.

In vitro bond strength tests, such as tensile or shear testing, depend on the application of a load to produce stress in the specimens until fracture occurs. The shear bond strength test was used, due to being quick and simple to perform ${ }^{(23-26)}$.

Five groups were prepared ; the samples received no treatment showed the least shear bond strength because unmodified ceramic surface produced a smooth and shallow porous surface. This weak bond strength was reflected in the pattern of failure of this group which showed adhesive failure.

In the group received hand grinding, zirconia ceramic surface preparation with diamond bur yielded the highest bond strength. Roughening with diamond bur was done at high speed to prevent hand piece vibration since this may cause cracks at the ceramic margins ${ }^{(27,28)}$.

The result of the present study was supported by a previous study which found that surface roughening by diamond bur yielded the highest bond strength ${ }^{(29)}$. Another study stated that grinding of the ceramic surface yielded a rougher surface than air abrasion and consequently resulted in higher bond strength ${ }^{(30)}$. This explained why hand grinding recorded higher bond strength than air abrasion.

A previous study discussed that rougher surfaces had higher surface free energy and provided a larger bonding area ${ }^{(31)}$. Bur preparation creates retentive grooves along which resin cement flow into these grooves and increase the bond strength ${ }^{(6)}$.

As opposed to the consequences of this study, a previous study concluded that no difference in shear bond strength between control group and the using of grinding tool. They clarified that there was no difference in surface topography and the resulted roughness ${ }^{(32)}$.

In the group received sandblasting, sandblasting with alumina was found to give good results with resin cement. In this study sandblasting for the zirconia discs was carried out using 50 $\mu \mathrm{m} \mathrm{Al}_{2} \mathrm{O}_{3}$ using an airborne particle-abrasive device. The discs were mounted at a distance of 10 $\mathrm{mm}$ in a metallic holder between the blasting tip and the surface of the sample. Sandblasting was done for $20 \mathrm{sec}$, with 3 bar pressure. This was carried out in accordance to many authors ${ }^{(8,33-35)}$.

It was assumed that $50 \mu \mathrm{m}$ aluminum oxide abrasive particles produced the highest roughness needed to improve the bonding. Also, sandblasting is considered a gentile procedure which less material is removed from the surface. The increase of bond strength is due to increase in micro roughness of sandblasted zirconia surface ${ }^{(36)}$. With a rougher surface, surface area, surface energy, surface wettability and flowing of resin cement in to micro retention areas increases so a stronger micromechanical interlock can be achieved ${ }^{(37)}$.

The consequence of our study was supported by a past study which presumed that the surface treatment of zirconia by sandblast resulted in increasing surface irregularities ${ }^{(33)}$. Also, in other studies they found that sand blasting increased the bond strength ${ }^{(38)}$. Another study stated that air abrasion creates surface roughening and increases bond strength ${ }^{(39,40)}$. Also, in a previous study it was found that treating surface of zirconia with $50 \mu \mathrm{mAl}_{2} \mathrm{O}_{3}$ resulted in high shear bond strength due to increase surface roughness and undercuts ${ }^{(41)}$.

However, in contrast to the results of this study, a previous study stated that air-abrasion did not increase bond strength, although the surface became rougher than the control group, most likely because of different grain size, or different pressure used in the study ${ }^{(42)}$. 
Another method of zirconia surface treatment was laser type $\mathrm{I}\left(\mathrm{CO}_{2}\right)$. The $\mathrm{CO}_{2}$ was utilized as proposed by numerous authors as anew surface treatment method. ${ }^{(5,34,43)}$ Selection of $\mathrm{CO}_{2}$ laser type was based on past finding ${ }^{(44,45)}$ which reported that $\mathrm{CO}_{2}$ laser revealed distinct surface alteration to zirconia surface, because wavelength of $\mathrm{CO}_{2}$ laser is absorbed by the ceramic ${ }^{(46)}$. During heat induction of ceramic surfaces, conchoidal tears appear. These tears provide mechanical retention. The parameters of the $\mathrm{CO}_{2}$ laser were selected according to past studies ${ }^{(44,45)}$.

It was found that the utilization of $\mathrm{CO}_{2}$ laser has a positive influence on shear bond strength (SBS). These results may be due to irregularities and the surface cracks on the surface of zirconia lead to increase penetration of resin ${ }^{(47)}$. This morphological change increased the bond strength. microcracks occurred facilitate the penetration of resin cement and improve adhesion ${ }^{(44)}$.

The area of roughness showed on $\mathrm{CO}_{2}$ laser treated samples due to laser energy discharge that caused surface change in form of pores caused by material removal by the laser. Increasing temperature result in melting of the ceramic surface and microcracks. Expansion of surface during melting and contraction during solidification occur . This stress due to temperature can cause superficial cracks ${ }^{(48)}$.

The consequences of our study were in harmony with previous studies which concluded that $\mathrm{CO} 2$ laser irradiation is effective method for treating zirconia surfaces. Laser is suggested as a new technique for treatment of zirconia ${ }^{(5,44,45)}$. In contrast to these results a previous study recorded that smooth and non-retentive surface was observed. but the results of these studies may be due to the different laser parameters used ${ }^{(12)}$.

In our study, another method of Zirconia surface treatment was laser type II (ER: YAG laser). Selection of Erbium YAG laser type in our present study was depend on previous studies ${ }^{(33,49,44)}$. who revealed that ER: YAG laser create micromechanical retention through roughening the surface of ceramics. In this study, an energy intensity of $200 \mathrm{~mJ}$ was selected following past studies who concluded that higher laser power result in melting, loss of material, and cracks. $200 \mathrm{~mJ}$ power was found to cause less melting ${ }^{(50,51)}$.

It was found that the use of Erbium: YAG laser increase shear bond strength due irregularities formation .Erbium: YAG laser increased roughness and increased the bond strength ${ }^{(46)}$. past studies found that ER: YAG irradiaton creates a rough surface ${ }^{(36,49,50)}$. The result of our study was supported by a previous study which concluded that the $200 \mathrm{~mJ} /$ pulse Erbium: YAG irradiation increased the bond strength and produced a rough surface ${ }^{(47)}$. Another author reported that $150 \mathrm{~mJ}, 10 \mathrm{~Hz}, 1 \mathrm{~W}$ and long pulse for 20 seconds ER: YAG laser irradiation on zirconia material increased the surface roughness ${ }^{(52)}$.

In compare, different studies post that Erbium: YAG irradiation does not increase bond strength ${ }^{(51,53)}$. Another author stated that $200 \mathrm{~mJ} /$ pulse, $10 \mathrm{~Hz}$ for $5 \mathrm{sec}$ Erbium: YAG laser irradiation decreased the bond strength ${ }^{(8)}$. Another study stated that irregularities and erosions created by ER: YAG laser have insufficient micromechanical retention and result in limited penetration of the resin ${ }^{(54)}$.

Other study explained that ER: YAG laser irradiation causes micro-explosions and creates debris that can strongly bond to ceramic surfaces and resin cements. This layer may weakly bond to the underlying surfaces and decrease the bond strength ${ }^{(6)}$.

Treatment of zirconia with Carbon dioxide and ERYAG lasers increased bond strength, but Carbon dioxide laser higher than ERYAG laser due to better absorption of $\mathrm{CO}_{2}$ by the surface of zirconia (44). This supported by a previous study which reported that $\mathrm{CO}_{2}$ laser resulted in higher shear bond strength, when compared to ER: YAG laser ${ }^{(47)}$. 


\section{CONCLUSIONS}

1. Treatment of Zirconia Surfaces with wet hand grinding or sandblasting increased shear bond strength.

2. Treatment of zirconia ceramic surfaces with Carbon dioxide and ERYAG lasers increased shear bond strength, , with the $\mathrm{CO}_{2}$ laser being higher than ERYAG laser.

\section{REFERENCES}

1. Shenoy A, Shenoy N. Dental Ceramics: An update. J Conserv Dent 2010; 13:195-203.

2. Spyropoulou P E, Giroux E C, Razzoog M E, Duff R E. Translucency of shaded zirconia core material. J Prosthet Dent. 2011; 105:304-7.

3. Lawson N C, Burgess J O. Dental ceramics: a current review. Compend Contin Educ Dent .2014; 35:161-6.

4. Sekhri S, Mitta 1 S, Gar G S. Tensile Bond Strength of SelfAdhesive Resin Cement After Various Surface Treatment of Enamel. J Clin Diag Res. 2016; 10: 1-4.

5. Kasraei S, Rezaei-SoufiL, Yarmohamadi E, Shabani A. Effect of CO2 and Nd:YAG Lasers on Shear Bond Strength of Resin Cement to Zirconia Ceramic. J Dent.2015; 12:686-94.

6. Subasi M G, Inan O. Evaluation of the topographical surface changes and roughness of zirconia after different surface treatments. Lasers Med Sci .2012; 27:735-42.

7. Liu L, Liu S, Song X, Zhu Q, Zhang W. Effect of Nd:YAG laser irradiation on surface properties and bond strength of zirconia ceramics. Lasers Med Sci. 2013; 7:1381-7.

8. Cavalcanti A N, Foxton R M, Watson T F, Oliveira M T, Giannini M, Marchi G M. Bond strength of resin cements to a zirconia ceramic with different surface treatments. Oper Dent.2009; $34: 280-7$.

9. Raigrodski AJ. Contemporary materials and technologies for all- ceramic fixed partial dentures: a review of the literature. J Prosthet Dent. 2004; 92:557-62.

10. Gomes AL, Ramos JC, Reigo SS, Montero J, Albaladejo A. Thermocycling effect on ceramic microshear bond strength to zirconia using ER: YAG and tribochemical silica coating as surface conditioning. Lasers Med Sci. 2015;30:787-95
11. Oba Y, Koizumi H, Nakayama D, Ishii T, Akazawa N, Matsumura H. Effect of silane and phosphate primers on the adhesive performance of a tri-n-butyl borane initiated luting agent bonded to zirconia. Dent Mater J. 2014;33:226-32.

12. Akın H, Ozkurt Z, Kırmalı O, Kazazoglu E,Ozdemir A. Shear bond strength of resin cement to zirconia ceramic after aluminum oxide sandblasting and various laser treatments. Photomed Laser Surg.2011; 29: 797-802.

13. Amario M ,Campidoglio M, Luciani L,Marchetti E,Baldi $M$.Effect of thermocycling on bond strength between dual -cured resin cements and zirconium-oxide ceramics.J Oral Sci.2010;52:425-30.

14. Senyilmaz DP, Palin WM, Shortall ACC, Burke FJ. The effect of surface preparation and luting agent on bond strength to a zirconium-based ceramic. Oper Dent .2007; 32:623-30.

15. Kitayama S, Nikaido T, Takahashi R, Zhu L, Ikeda M, Foxton RM, Sadr A, Tagami J. Effect of primer treatment on bonding of resin cements to zirconia ceramic. J Dent Mater. 2010; 26:426-32.

16. Yoshida K, Tsuo Y, Atsuta M. Bonding of dual-cured resin cement to zirconia ceramic using phosphate acid ester monomer and zirconate coupler. J Biomed Mater Res B Appl Biomater. 2006; 77: 28-33.

17. Atsu SS, Kilicarslan MA, Kucukesmen HC, Aka PS. Effect of zirconium-oxide ceramic surface treatments on the bond strength to adhesive resin. J Prosthet Dent .2006; 95: 430-6.

18. Tanaka R, Fujishima A, Shibata Y, Manable A, Miyazaki T. Cooperation of phosphate monomer and silica modification on zirconia. J Dent Res. 2008; 87:666-70.

19. De Souza GM, Thompson VP, Braga RR.Effect of metal primers on micro-tensile bond strength between zirconia and resin cements. J Prosthet Dent. 2011; 105:296-303.

20. Derand T, Molin M, Kvam K. Bond strength of composite luting cement to zirconia ceramic surfaces. J Dent Mater. 2005; 21:1158-62.

21. Matinlinna J P, Lassila LV, Vallittu PK. Pilot evaluation of resin composite cement adhesion to zirconia using a novel silane system. Acta Odontol Scand.2007; 65:44-51.

22. Blatz MB, Chiche G, Holst S, Sadan A. Sadan. Influence of surface treatment and simulated aging on bond strengths of luting agents to zirconia. Quintessence Int. 2007; 38:745-53. 
23. Trup V, Sen D, Tuncelli B, Goller G, Ozcan M. Evaluation of air-particle abrasion of Y-TZP with different particles using micro-structural analysis. Aust Dent J. 2008; 27:44854.

24. Dbradovi C, Djurici K, Medi V, Dodi S, Gavrilov D, Antonijevi D, Zrili M. Dilemmas in zirconia bonding: A review. Srp Arh Celok Lek .2013; 141:395-401.

25. Bitter K, Priehn K, Martus P, Kielbassa A. In vitro evaluation of push out bond strengths of various luting agents to tooth-colored posts. J Prosth Dent. 2006; 95:302-10.

26. Yoshida K, Tsuo Y, Atsuta M. Bonding of dual-cured resin cement to zirconia ceramic using phosphate acid ester monomer and zirconate coupler. J Biomed Master Res Part B: Appl Biomater.2006; 77:28-33.

27. Reston EG, Filho SC, Arossi G, Cogo RB, Rocha CS, Closs LQ. Repairing Ceramic Restorations: Final Solution or Al- ternative Procedure? Operative Dentistry.2008; 33: 461-6.

28. Kussano C, Bonfante G, Batista J, Nogueira Pinto J. Evaluation of Shear Bond Strength of Composite to Porce- lain According to Surface Treatment. Braz Dent J.2003;14: 132- 5 .

29. Tabatabaei M H, Chiniforush N, Namdar S F. Effects of different ceramic primers and surface treatments on the shear bond strength of restorative composite resin to zirconium. Laser Therapy. 2018; 27: 111-7.

30. Derand P, Derand T. Bond strength of luting cements to zirconium oxide ceramics. Int J Prosthodon.2003; 13:131-5.

31. Yamagushi H, Satoshi Ino S, Hamano N, Okada Sh, Terana ka T. Examination of bond strength and mechanical properties of Y-TZP zirconia ceramics with different surface modifications. Dental Materials Journal.2012; 31: 472-80.

32. Qeblawi D M, Muñoz CA, Brewer J D, Monaco EA. The effect of zirconia surface treatment on flexural strength and shear bond strength to a resin cement. JProsthet Dent. 2010; 103:210-20.

33. Juntavee N, Juntavee A, Yothajun T. Shear bond strength of resin adhesive to laser treated surface of yttria tetragonal zirconia polycrystalline. A P R D. 2017; 3:10-5.

34. Tanıs M C, Akçaboy C. Effects of Different Surface Treatment Methods and MDP Monomer on Resin Cementation of Zirconia Ceramics an in Vitro Study. J Lasers Med Sci .2015; 6:174-81.
35. Zandparsa R, Talua N A, Finkelman M D, Schaus S E. An in Vitro comparison of Shear Bond Strength of Zirconia to Enamel Using Different Surface Treatments. J of Prosthond .2014; 23: 117-23.

36. Demir N, Subası M G, Ozturk A N. Surface Roughness and Morphologic Changes of Zirconia Following Different Surface Treatments. Photomed Laser Surg. 2012; 30: 339-45.

37. Papia E, Larsson C, Toit M, Steyern PV. Bonding between oxide ceramics and adhesive cement systems: a systematic review. J Biomed Mater Res B: Appl Biomater. 2013;102:395-413.

38. Abu-Eittah M R. Assessment of Different Surface Treatments Effect on Surface Roughness of Zirconia and Its Shear Bond Strength to Human Dentin. Life Sci J.2012; 9:1792-1803.

39. Yang B, Lange-Jansen HC, Scharnberg M, Wolfart S, Ludwig K, Adelung R, et al. Influence of saliva contamination on zirconia ceramic bonding. Dent Mater.2008; 24:508-13.

40. Yang B, Scharnberg M, Wolfart S, Quaas AC, Ludwig $\mathrm{K}$, Adelung R, et al. Influence of contamination on bonding to zirconia ceramic. JBiomed Mater Res B Appl Biomater.2007; 81:283- 9 .

41. Dawood R M, Ibraheem A F. Evaluation of shear bond strength of zirconia to tooth structure after different zirconia surface treatment techniques. J Bagh Coll Dent. 2015; 27:77-85.

42. de Oyague RC, Monticelli F, Toledano M, Osorio E, Ferrari $\mathrm{M}$ and Osorio R. Influence of surface treatments and resin Oxide ceramic. Dental Materials. 2009; 25: 172-9.

43. Al-Harbi F A, Ayad N M, Khan Z A, Mahrous AA, Morgano S M. In vitro shear bond strength of Y-TZP ceramics to different core materials with the use of three primer/resin cement systems. J Prosthet Dent.2015; 1-6.

44. Kasraei S, RezaeiSoufi L, Heidari B, Vafaee F. Bond strength of resin cement to $\mathrm{CO} 2$ and Er:YAG laser treated zirconia ceramic. Restor Dent Endod. 2014; 39:296- 302.

45. Ural C, Kalyoncuoglu E, Balkaya V. The effect of different power outputs of carbon dioxide laser on bonding between zirconia ceramic surface and resin cement. Acta Odontol Scand .2012; 70: 541-6.

46. Chen JR, Oka K, Kawano T, Goto T, Ichikawa T. Carbon dioxide laser application enhances the effect of silane primer on the shear bond strength between porcelain and composite resin. Dent Mater J. 2010;29:731-7. 
47. Akyil M, Uzun I, Bayindir F. Bond strength of resin cement to yttrium-stabilized tetragonal zirconia ceramic treated with air abrasion, silica coating, and laser irradiation. Photomed Laser Surg .2010; 28:801- 8 .

48. Arami S, Tabatabae MH, Namdar SF, Chiniforush N. Effects of Different Lasers and Particle Abrasion on Surface Characteristics of Zirconia Ceramics.J DENT Tehran. 2014;2:233-41.

49. Lin Y, Song X, Chen Y, Zhu Q, Zhang W. Effect of Er:YAG Laser Irradiation on Bonding Property of Zirconia Ceramics to Resin Cement. Photomed Laser Surg. 2013; 31: 619-25.

50. Cavalcanti A N, Pilecki P, Foxton R M,Watson T F,Oliveira M T, Gianinni M, Marchi G M. Evaluation of the Surface Roughness and Morphologic Features of Y-TZP Ceramics after Different Surface Treatments. Photo med Laser Surg.2009; 27:473-9.

51. Foxton RM, Cavalcanti AN, Nakajima M, Pilecki P, Sherriff M, Melo L, Watson TF. Durability of resin cement bond to aluminium oxide and zirconia ceramics after air abrasion and laser treatment. J Prosthodont. 2011;20: 84-92.

52. Akin H, Tugut F, Akin GE, Guney U, Mutaf B. Effect of Er:YAG laser application on the shear bond strength and micro leakage between resin cements and Y-TZP ceramics. Lasers Med Sci. 2012; 27:333-8.

53. Erdem A, Akar GC, Erdem A, Kose T. Effects of different surface treatments on bond strength between resin cements and zirconia ceramics. Oper Dent 2014;39:118-27.

54. Özkurt Z, Kazazoğlu E. Clinical success of zirconia in dental applications. J Prosthodont. 2010; 19:64-8 